
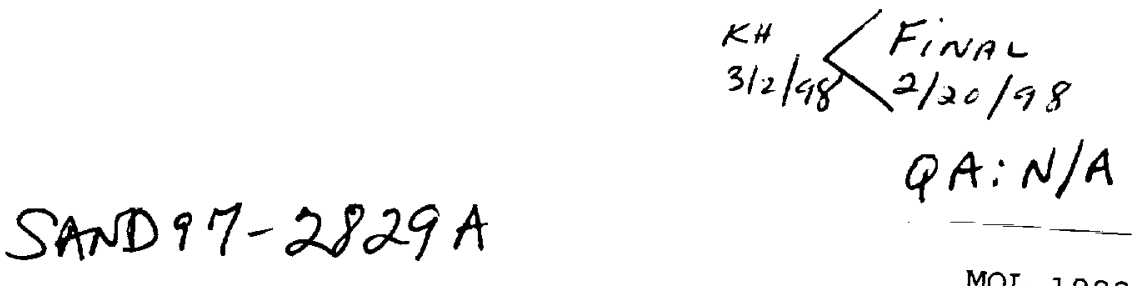

MOL . 19980504.0196

\title{
DEVELOPMENT OF ABSTRACTION/TESTING ACTIVITIES FOR TSPA-VA OR HOW PA, SITE, AND DESIGN CAME TO CONSENSUS WITHOUT COMING TO BLOWS
}

\author{
Holly A. Dockery \\ Sandia National Laboratories (CRWMS M\&O) \\ P.O. Box 5800 \\ Albuquerque, NM 8785 \\ (505)848-0730
}

Robert W. Andrews

Duke Engineering and Services (CRWMS M\&O)

1180 Town Center Drive, MS423/123

Las Vegas, NV 89134

(702)295-5549

\section{INTRODUCTION}

The Viability Assessment (VA) for the potential repository system includes four major components: three components are related to repository and waste package design, plan and cost to complete a license application, and an estimate of costs to construct the repository. The fourth component is "a total-system performance assessment based on the design concept and scientific data and analysis available by September 30,1998 , describing the probable behavior of the repository in the Yucca Mountain geological setting relative to the overall system performance standards."

During FY97-98, a series of abstraction/testing (A/T) activities were initiated to identify and construct appropriate numerical or analytical representations of components of the potential Yucca Mountain repository system to assure the development of a valid, defensible total-system performance assessment (TSPA) for TSPA-VA. This objective required that Performance Assessment (PA) incorporate the most complete and current information available from the Project. However, due to time and resource constraints, the model development had to be focused on only those issues that were expected to have the most influence on long-term performance. Also, the essential behavior of key processes (defined relative to the contribution that each process makes to long-term performance of the repository system) of each component be had to be captured in a computationally efficient manner. Following is a general discussion of the activities undertaken in FY97 to develop the models ultimately to be used in TSPA-VA.

\section{PROBLEM STATEMENT}

The models to be used to perform the TotalSystem Performance-Assessment-Viability Assessment (TSPA-VA) are generally expected to be formulated as "abstractions" from more detailed process models. In the case of a TSPA, an abstraction is defined as a simplified/idealized model that reproduces or bounds the essential elements of a more detailed process model. The inputs for an abstraction may be those that form a subset of those required for a process model, or the abstraction may be a response function derived from intermediate results. However, the abstracted form must capture uncertainty and variability. The abstractions must also be tested against process models to ensure their validity. The success of the abstraction process depends heavily on the effective integration of information from all elements of the project, including site characterization, design, and PA.

Abstractions are used because the probabilistic/ stochastic nature of the Yucca Mountain TSPA analyses requires computationally efficient models. The intent of the abstraction process is to retain key aspects of process models, while producing results usable in multiple realization probabilistic models.

The total-system performance assessment performed for the TSPA-VA will be constructed of models developed to represent processes and features of both the natural and the engineered system. Although the responses of the components are strongly inter-dependent, the PA analysts separated the processes into somewhat artificial components to facilitate analysis. These components were: 1) Unsaturated Zone (UZ) Flow, 2) UZThermohydrologic Flow, 3) Near Field Geochemical Environment, 4) Waste Package Degradation, 5) Waste Form Alteration and Mobilization, 6) Unsaturated Zone Transport, 7) Saturated Zone Flow and Transport, 8) Nuclear Criticality, and 9) Biosphere. A separate $\mathrm{A} / \mathrm{T}$ activity was defined for each of the nine components defined above.

\section{RESULTS AND SUMMARY}

In order to meet the goal of constructing a valid, defensible TSPA-VA, the A/T activities were designed to integrate the work of PIs from site characterization, design, environmental programs, and performance assessment. In order to achieve this integration, 
analysts from each these areas of the project were identified to participate in all aspects of the $A / T$ activities. These activities had 3 major elements.

The first element included the planning needed to identify a preliminary list of relevant issues for the subject component and to define the activities to be accomplished in a workshop. The next step in the A/T activity was to hold a workshop where issues were further explained and developed. These issues were prioritized based on criteria previously shown to be most important to repository performance, and analysis plans were developed to address those high priority issues. The last step was to perform the set of analyses proposed in the analysis plans to develop the high priority parameters, models of processes, and alternate conceptualizations for use in the TSPA-VA.

The entire suite of workshops was conducted between December 1996 and June 1997. As each workshop was held, the workshop planners progressively developed more effective methods of facilitating interactions among the participants and of developing information most useful to PA model development. One of the main benefits of the workshops was the enhanced communication among the site characterization, design, and PA principal investigators. Development and usage of well-defined and very specific prioritization criteria enabled the PA analysts to more clearly articulate the exact needs of the PA modeling effort. It also helped the Project redirect some aspects of certain data collection and process model development activities to respond to more critical PA needs. The teams that were formed to write and implement the analysis plans had representatives from site, design, and PA. This broad membership helped ensure the continuation of the integration process as the models were developed and as new information was incorporated.

The final process was effective in accomplishing a higher degree of cross-project integration than had occurred in previous YMP TSPA development exercises. Because of this integration, the TSPA-VA models will more accurately represent the consensus of YMP participants. A similar process will be used for the TSPA for the License Application with a stronger emphasis on the documentation of rationale for decisions made within the context of the activity. 